\title{
Production of thermal energy in University building greenhouses in cold climate conditions
}

\author{
Eusébio Conceição ${ }^{1,2^{*}}$, João Gomes ${ }^{2}$, Maria Manuela Lúcio $^{1}$, and Hazim Awbi $^{3}$ \\ ${ }^{1}$ FCT - University of Algarve, Campus de Gambelas, 8005-139 Faro, Portugal \\ ${ }^{2}$ CINTAL, Campus de Gambelas, 8005-139 Faro, Portugal \\ ${ }^{3}$ School of Built Environment, University of Reading, Reading, RG6 6AW, UK
}

\begin{abstract}
The present work focuses on the production of thermal energy in University building greenhouses in cold climate conditions. The building model uses a system of energy and mass balance integral equations, which are solved by the Runge-Kutta-Felberg method with error control. This numerical study is about the thermal behaviour of a university building with complex topology, in winter and transient conditions. The thermal comfort of the occupants, using the Predicted Mean Vote index, and the indoor air quality, using the carbon dioxide concentration, are evaluated. This building has 319 compartments distributed by four floors and it is equipped with one internal greenhouse in the third floor. This greenhouse is located on the south facing facade and the heated air in this space will be transported to compartments located on the north facing façade. The spaces subject to the influence of the heated air coming from the greenhouse improve the level of thermal comfort of its occupants. The level of indoor air quality in occupied spaces is acceptable according to international standards.
\end{abstract}

\section{Introduction}

The use of internal greenhouses in buildings to reduce winter energy consumption is a passive strategy that has been widely used for the past 50 years. These passive solar heating systems can contribute to increase solar heat gains, reducing space heating energy demand and the related use of fossil fuels [1,2]. Research on the impact of the use of sunspaces on buildings has been ongoing over the years. The energy savings obtained with the application of these systems were analyzed in the works of Chiesa et al. [3], Ignjatovic et al. [4], Puertolas et al. [5], and Ulpiani et al. [6].

This work uses a numerical model, developed by the authors over the past twenty years, which is based on a system of energy and mass balance integral equations and works under transient conditions (as example, please see the works of Conceição et al. [7], [8], and Conceição and Lúcio [9]). The building geometry is developed by Computing Aid Design and all equations will be established by the numerical software using this geometry. This numerical model has been used to evaluate the thermal comfort of occupants of buildings when, for example, it was applied internal greenhouses [10], implemented passive and active solutions [8] or considering solar heat gains from different orientations [11].
The PMV (Predicted Mean Vote) and the PPD (Predicted Percentage of Dissatisfied) comfort indexes were developed by Fanger [12] to be applied in airconditioned interior spaces of buildings located in temperate climates. The ANSI/ASHRAE Standard 55 [13] and ISO 7730 [14] use these indexes to assess the level of thermal comfort in the compartments of buildings that use air conditioning systems. The software used in this work calculates these indexes (PMV and PPD) using the indoor air temperature, indoor air velocity, indoor air relative humidity, clothing level and activity level. The evaluation of thermal comfort of building's occupants obtained by this software can be seen, as example, in the studies of Conceição and Lúcio [15] and Conceição et al. [16][18].

The concentration of carbon dioxide is normally used to evaluate the level of indoor air quality [19], [20]. The ASHRAE 62.1 standard considers that a concentration of the carbon dioxide below $1800 \mathrm{mg} / \mathrm{m}^{3}$ indicates an acceptable level of indoor air quality [21]. The indoor air renovation is obtained by a ventilation system that uses the insufflation of the outside air in the compartments to be air-conditioned and the respective extraction of the contaminated air from these compartments. For more details, please see the studies of Conceição et al. [22]-[24].

* Corresponding author: econcei@ualg.pt 
In this numerical study, a whole building dynamic response software, developed by the authors, is used to assess the implementation of a passive solar solution on a university building and its effect on the thermal comfort of the occupants. This solution is based on the production of thermal energy in a sunspace of the university building located on its south-facing facade in order to take advantage of its greenhouse effect and thus preheat the air to be distributed by the compartments located on its north-facing facade. The numerical study is made for a winter typical day and it is presented for a selected set of compartments.

\section{Numerical Model}

The numerical simulation was performed with software, developed by the authors, that simulates the thermal response of whole building. This software was validated, using school buildings, for winter conditions in Conceição et al. [25] and for summer conditions in Conceição and Lúcio [26].

The numerical model is founded on:

- the balance of energy integral equations;

- the balance of mass integral equations.

The energy balance integral equations are taken for:

- the indoor air of the compartments;

- the transparent (windows) bodies of the building;

- the interior and surroundings bodies of the building;

- the opaque (walls and doors) bodies of the building.

Several layers are considered for the opaque surfaces and one layer is considered for the transparent surfaces. The compartments surrounding boundaries surfaces are also considered.

The mass balance integral equations are taken into consideration for the water vapour and the air contaminants. These equations are developed for the spaces of the buildings and the solid matrix (opaque and interior bodies).

The resolution of the equations system is done by the Runge-Kutta-Felberg method with error control.

In the system of integral equations, the numerical model considers the phenomena of heat transmission by conduction, convention and radiation, which occur in opaque and transparent bodies.

In opaque bodies, the conduction inside the different layers, and the convention and radiation on the outer surfaces in contact with the external environment are verified. In the inner layers, the thickness and thermal conductivity of each layer are considered. In the layer in contact with the external environment, natural, forced and mixed convention are considered, which values are calculated using dimensionless coefficients for vertical, horizontal and inclined surfaces. On the outer surfaces of opaque bodies, radiative phenomena are also considered, namely solar radiation and heat exchanges. In the case of solar radiation, the software calculates direct and diffuse radiation on surfaces with an arbitrary inclination throughout the day. Therefore, on the outer surfaces of opaque bodies, incident, reflected and absorbed radiation are considered. In heat exchanges, in confined spaces, the view factors verified between all surfaces are calculated.

In transparent bodies, in addition to the same conductive, convective and radiative phenomena, the transmission of radiation through these surfaces is also considered. Here two aspects have to be considered: calculation of the radiative properties in the glasses and the distribution of the radiation transmitted through the glasses by the different opaque surfaces inside each compartment. Shading phenomena are considered in all radiative calculations $[8,11,15]$.

The numerical model uses the three-dimensional virtual building obtained from the Computer Aided Design software, in addition to generating the energy and mass equations system, to also calculate the area of the opaque and transparent surfaces, identify the thermal properties of these surfaces and calculate the volume of the compartments.

The inputs of the numerical software are the:

- building geometry (opaque, transparent and interior bodies);

- building bodies properties;

- outdoor air temperature;

- outdoor air relative humidity;

- outdoor wind direction

- outdoor wind velocity;

- outdoor dioxide carbon concentration;

- occupation;

- ventilation cycles;

- personal parameters (clothing and activity levels);

- among others.

The outputs of the numerical software are the:

- solar radiation evolution;

- radiation heat exchange;

- convection coefficients;

- indoor air temperature;

- indoor air velocity;

- dioxide carbon concentration;

- $\quad$ PMV and PPD thermal comfort indexes;

- among others.

\section{Numerical Methodology}

The numerical study was applied in a University building, mainly consisting of classrooms, laboratories, offices and other spaces. The building is divided into 319 spaces, distributed by four floors, and is constituted by 329 transparent surfaces (windows) and 3585 opaque surfaces (internal and external walls, doors, and others). The simulation was performed considering a typical winter day (21 $1^{\text {st }}$ December) and for a building (Figure 1) located in a region with a latitude of $39^{\circ}$ North in a Mediterranean-type climate. 


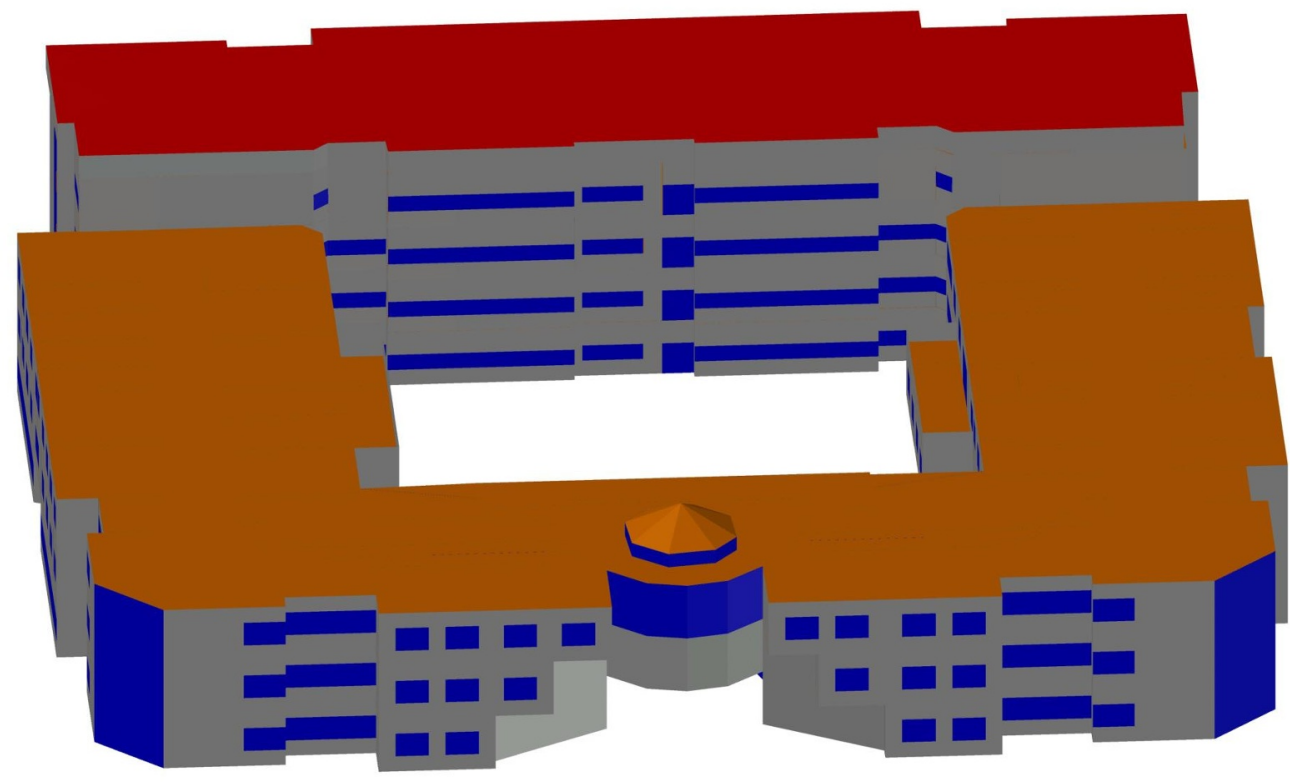

Figure 1. Perspective of the south view of the university building.

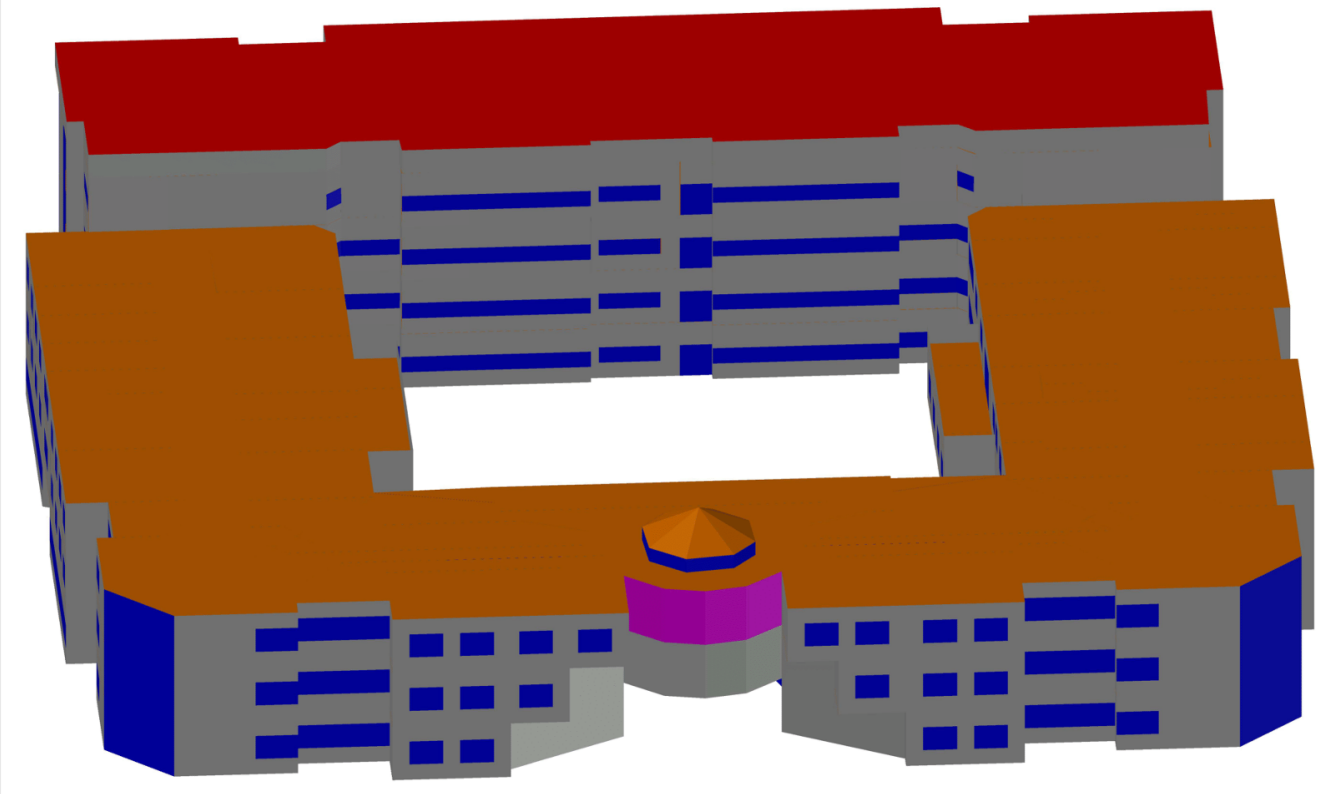

Figure 2. Perspective of the south view of the university building with an internal greenhouse located on the third floor (magenta colour).

Two situations were analysed: the building has no internal greenhouse (Figure 1) and the building has an internal greenhouse located on a third floor space on the south facing façade (Figure 2). In Figure 1, the grey colour is associated to opaque surfaces, blue colour is associated to transparent surfaces (windows), and red and orange colours are associated to different type of roofs. In Figure 2 the grey colour is associated to opaque surfaces, blue colour is associated to transparent surfaces (windows), red and orange colours are associated to different type of roofs and magenta colour is associated to horizontal the internal greenhouse space located on third floor. 
For the situation without internal greenhouse, the airflow, in the inlet process, comes from the outside environment to the occupied spaces and in the outlet process comes from the occupied spaces to the outside environment. For the situation with internal greenhouse, the airflow, in the inlet process, comes from the greenhouse space to the occupied spaces and in the outlet process comes from the occupied spaces to the outside environment. In this last situation, the airflow topology selected is as follows in Figure 3. The heated airflow comes from the greenhouse (space 150), located south, and it is transported to the rooms (spaces 239, 245, 274 and 276) located north. These rooms were chosen as representative of the results obtained.

The selection of the airflow rate took into account the situation of occupation or non-occupation of spaces. When the spaces are occupied, the airflow rate used was calculated according to the Portuguese standard [27]. According to this standard, the ventilation rate is calculated according to the number of occupants $n$, that is, $0.0072 \cdot n \mathrm{~m}^{3} / \mathrm{s}$. When spaces are not occupied, it was used an airflow rate of one air renewal per hour. The temperature of the air blown into the spaces is that supplied by the greenhouse.

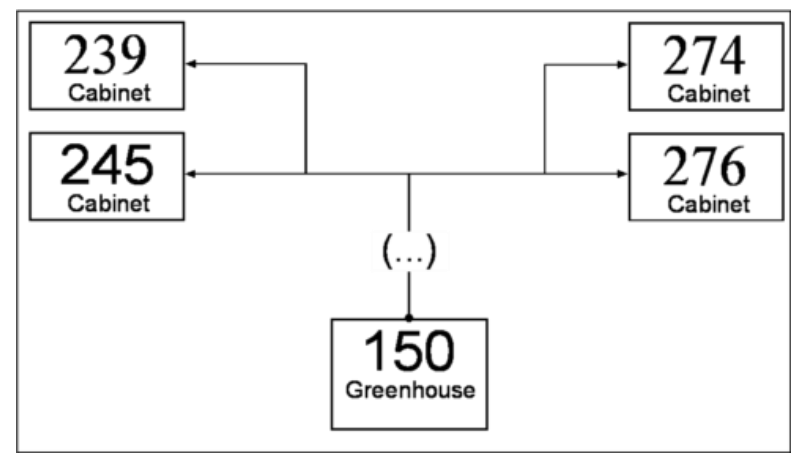

Figure 3. Circuits of the airflow to certain rooms with a greenhouse.

In the numerical simulation, it was considered that the classrooms, laboratories and offices are occupied, in general, by periods of 90 minutes. The breaks considered between the occupation periods have a duration of 15 minutes. It was considered that the classrooms and laboratories have an occupancy of 15 persons and the offices 2 persons. As the numerical simulation was performed for typical winter conditions, it was defined a clothing level of 1 clo [14]. The level of activity considered was 1.2 met [14].

The concentration of carbon dioxide in the outdoor environment is $500 \mathrm{mg} / \mathrm{m}^{3}$, a reference value measured in the region where the building is located.

The numerical simulation evaluates the thermal behaviour of all compartments in the building. The input data related to the external environmental conditions (air temperature, relative humidity, wind direction and speed) were obtained by a weather station located in the vicinity of the building.

\section{Results}

In this section, the results of indoor air quality, evaluated by the dioxide carbon concentration, indoor air temperature and thermal comfort of occupants, evaluated by the PMV index, in the rooms are presented and discussed.

The entire compartments of the building were simulated. However, only the results of some spaces located on the third floor will be presented.

The evolution of carbon dioxide concentration is shown in Figure 4 in the selected spaces located on the north façade of the third floor, obtained for a typical winter day conditions. The results demonstrate that the level of indoor air quality in these spaces is acceptable according to the standard [21].

The evolution of air temperature is shown in Figure 5 in the selected spaces located on the north façade of the third floor, obtained for a typical winter day conditions. In the Figure 5, it is possible to observe the evolution of the air temperature in the selected spaces $(239,245,274$ and 276) when space 150 is used as an internal greenhouse and when no internal greenhouse is used.

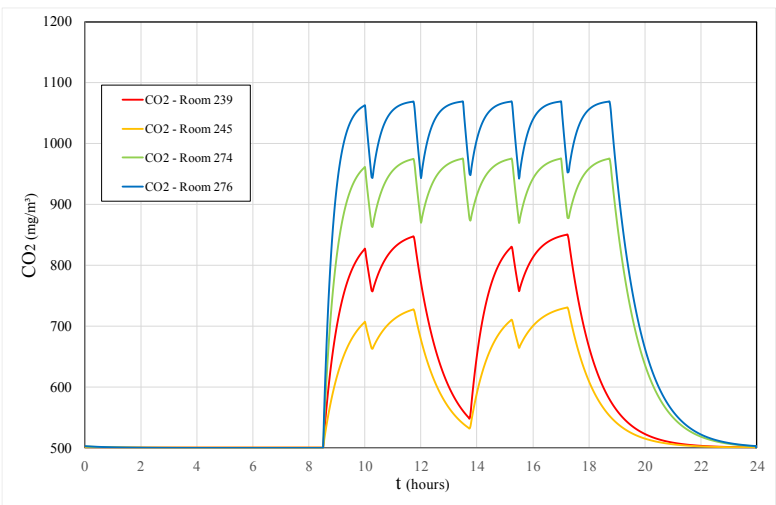

Figure 4. Evolution of carbon dioxide concentration $\left(\mathrm{CO}_{2}\right)$ obtained in the rooms located on the north façade of the third floor for a typical winter day conditions.

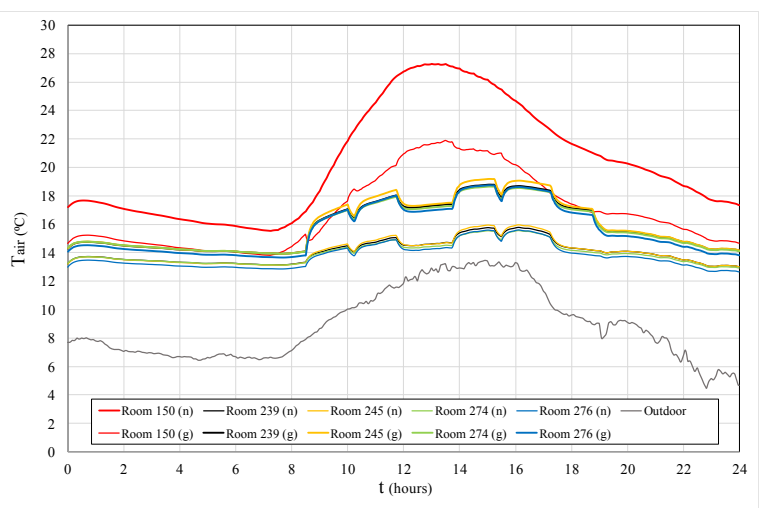

Figure 5. Evolution of air temperature ( $\mathrm{T}_{\text {air }}$ ) obtained in the rooms located on the third floor and outdoor, for a typical winter day conditions, when there is an internal greenhouse $(\mathrm{g})$, space 150 , or not $(\mathrm{n})$.

The results show that room 150, with windows facing south, has higher temperatures, on average $4^{\circ}$ to 
$13^{\circ} \mathrm{C}$, than the rooms analyzed with windows facing north. When room 150 operates as an internal greenhouse, its air temperature drops from $2^{\circ}$ to $5^{\circ} \mathrm{C}$. However, it still remains, on average, $8^{\circ} \mathrm{C}$ above the outdoor air temperature. This means that there is still availability of thermal energy in this space to supply heated air to the occupied spaces, if the airflow rate is increased.

The air temperature in the occupied spaces when using the internal greenhouse is, on average, $3^{\circ} \mathrm{C}$ higher than its air temperature in those when the internal greenhouse is not used. In this situation, part of the thermal energy needed to heat these spaces is provided by an essentially natural and low-consumption ventilation system that uses a passive solution to take advantage of the incident solar radiation.

The evolution of PMV index is shown in Figure 6 in the selected spaces located on the north façade of the third floor, obtained for a typical winter day conditions. In the Figure 6, it is possible to observe the evolution of the PMV index in the selected spaces $(239,245,274$ and 276) when space 150 is used as an internal greenhouse and when no internal greenhouse is used.

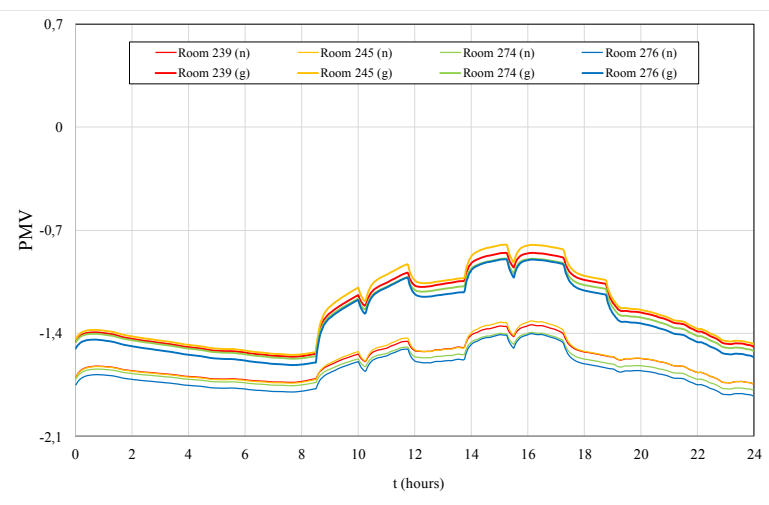

Figure 6. Evolution of PMV index obtained in the rooms located on the third floor, for a typical winter day conditions, when there is an internal greenhouse (g), space 150, or not (n).

When using the internal greenhouse, the results show that the evolution of the PMV index in occupied rooms improves in relation to that observed when the internal greenhouse is not used. In this situation, it appears that the level of thermal comfort is not acceptable due to negative values of the PMV index. However, these values are very close to the limit imposed by category C (PMV $\geq-0.7)$ [14].

It is noted, therefore, that the spaces subject to the influence of the heated air from the internal greenhouse improve the levels of thermal comfort of the occupants. In the case under study, it is necessary to increase the airflow rate to ensure that this level of thermal comfort is acceptable, at least within the category C of ISO 7730 [14]. The results also show that this can be achieved given the amount of thermal energy still available in the internal greenhouse (room 150).

\section{Conclusions}

This article focused on the implementation of a passive solution for the production of thermal energy in an internal greenhouse located on the south-facing façade of a university building. The cold air from the outside enters this space, is heated and then distributed to spaces located on the north facade in order to improve the thermal comfort of its occupants.

The internal greenhouse increased an average of $3^{\circ} \mathrm{C}$ the indoor air temperature, improved the PMV index to values close to the acceptable level according to category $C$ [14] and contribute to guarantee acceptable level of indoor air quality [21]. It can thus be seen that the use of the internal greenhouse has a positive effect of improving the thermal comfort of the occupants of the spaces analyzed. However, it is necessary to increase the airflow rate of the ventilation system in order to take advantage of the availability of existing thermal energy to place the level of thermal comfort, at least, within category C [14].

\section{Acknowledgement}

The authors would like to acknowledge to the project (SAICT-ALG/39586/2018) from Algarve Regional Operational Program (CRESC Algarve 2020), under the PORTUGAL 2020 Partnership Agreement, through the European Regional Development Fund (ERDF) and the National Science and Technology Foundation (FCT).

\section{References}

[1] M. Guasco, M. Orlanno, C. Piccardo, A. Giachetta, and A. Dodoo, "Design optimization of a building attached sunspace through experimental monitoring and dynamic modelling," E3S Web of Conferences, 172, 03010, 2020.

[2] M. Fernandez-Antolin, J. del Río, V. Costanzo, F. Nocera, and R. Gonzalez-Lezcano, "Passive design strategies for residential buildings in different Spanish climate zones," Sustainability, 11, 4816, 2019.

[3] G. Chiesa, M. Simonetti, and G. Ballada, "Potential of attached sunspaces in winter season comparing different technological choices in Central and Southern Europe," Energy Build., 138, 377-395, 2017.

[4] D. Ignjatovic, M. Popovic, and J. Kavran, "Application of sunspaces in fostering energy efficiency and economical viability of residential buildings in Serbia," Energy Build., 98, 3-9, 2015.

[5] R. Puertolas, J. Gonzalez, S. Castro, P. Benito, and C. Arrebola, "A bioclimatic building in Madrid: Analysis of the thermal response and long-term comfort indices review," Developments in the Built Environment, 3, 100015, 2020.

[6] G. Ulpiani, D. Giuliani, A. Romagnoli, and C. di Perna, "Experimental monitoring of a sunspace applied to a NZEB mock-up: Assessing and 
comparing the energy benefits of different configurations," Energy Build., 152, 194-215, 2017.

[7] E. Conceição, J. Gomes, and H. Awbi, "Influence of the airflow in a solar passive building on the indoor air quality and thermal comfort levels," Atmosphere, 10, 766, 2019.

[8] E. Conceição and M. Lúcio, "Numerical simulation of passive and active solar strategies in building with complex topology," Build. Simul., 3, 245-261, 2010.

[9] E. Conceição, J. Farinho, and M. Lúcio, "Evaluation of indoor air quality in classrooms equipped with cross-flow ventilation," Int. J. Vent., 11(1), 53-68, 2012.

[10]E. Conceição, M. Lúcio, and M. Lopes, "Application of an indoor greenhouse in the energy and thermal comfort performance in a kindergarten school building in the south of Portugal in winter conditions," WSEAS Trans. Environ. Dev, 4, 644654, 2008.

[11]E. Conceição and M. Lúcio, "Numerical study of the thermal efficiency of a school building with complex topology for different orientations," Indoor Built Environ., 18, 41-51, 2009.

[12]P. Fanger, Thermal comfort: analysis and applications in environmental engineering. Danish Technical Press, Copenhagen, Denmark, 1970.

[13]ANSI/ASHRAE Standard 55, Thermal Environmental Conditions for Human Occupancy. American Society of Heating, Refrigerating and Air-Conditioning Engineers: Atlanta, GA, USA, 2017.

[14] ISO 7730, Ergonomics of the thermal environments - Analytical determination and interpretation of thermal comfort using calculation of the PMV and PPD Indices and Local Thermal Comfort Criteria. International Standard Organization: Geneva, Switzerland, 2005.

[15] E. Conceição, and M. Lúcio, "Numerical simulation of the application of solar radiant systems, internal airflow and occupants' presence in the improvement of comfort in winter conditions," Buildings, 6(3), 38, 2016.

[16] E. Conceição, M. Lúcio, A. Ruano, and E. Crispim, "Development of a temperature control model used in HVAC systems in school spaces in Mediterranean climate," Build. Environ., 44, 871877, 2009.

[17]E. Conceição, A. Nunes, J. Gomes, and M. Lúcio, "Application of a school building thermal response numerical model in the evolution of the adaptive thermal comfort level in the Mediterranean environment," Int. J. Vent., 9(3), 287-304, 2010.

[18]E. Conceição, J. Gomes, and A. Ruano, "Application of HVAC systems with control based on PMV index in university buildings with complex topology," IFAC PapersOnLine, 51-10, 20-25, 2018.
[19]A. Asif, M. Zeeshan, and M. Jahanzaib, "Indoor temperature, relative humidity and $\mathrm{CO}_{2}$ levels assessment in academic buildings with different heating, ventilation and air-conditioning systems," Build. Environ., 133, 83-90, 2018.

[20]A. Persily and L. de Jonge, "Carbon dioxide generation rates for buildings occupants," Indoor Air, 27, 868-879, 2017.

[21]ANSI/ASHRAE Standard 62-1, Ventilation for Acceptable Indoor Air Quality. American Society of Heating, Refrigerating and Air-Conditioning Engineers: Atlanta, GA, USA, 2016.

[22]E. Conceição, M. Lúcio, V. Vicente, and V. Rosão, "Evaluation of local thermal discomfort in a classroom equipped with cross flow ventilation," Int. J. Vent., 7(3), 267-277, 2008.

[23] E. Conceição, S. Rosa, A. Custódio, R. Andrade, M. Meira, and M. Lúcio, "Study of airflow around occupants seated in desks equipped with upper and lower air terminal devices for slightly warm environments," HVAC\&R Res., 16(4), 401-412, 2010.

[24]E. Conceição, M. Lúcio, and H. Awbi, "Comfort and airflow evaluation in spaces equipped with mixing ventilation and cold radiant floor," Build. Simul., 6, 51-67, 2013.

[25]E. Conceição, A. Silva, and M. Lúcio, "Numerical study of thermal response of school buildings in winter conditions," In Proceedings of the $9^{\text {th }}$ Conference on Air Distribution in Rooms (Roomvent 2004), Coimbra, Portugal, September 5-8, 2004.

[26]E. Conceição and M. Lúcio, "Numerical study of thermal response of school buildings in summer conditions," In Proceedings of the $8^{\text {th }}$ International Conference and Exhibition on Healthy Buildings (HB 2006), Lisbon, Portugal, June 4-8, 2006.

[27]Portaria 353-A, Requisitos de ventilação $e$ qualidade do ar interior. Diário da República n. ${ }^{\circ}$ 235/2013, $1^{\circ}$ Suplemento, Série I de 2013-12-04, 2013. (in Portuguese) 